$$
\text { المجلة الدولية للدراسـات اللغوية والأدبية العربية }
$$

International Journal for Arabic Linguistics and Literature Studies (JALLS)

\title{
Study of the Current State and Practice of Arabic Language Education in Academic Departments \\ (Case study: Arabic Language and Islamic Studies Department of Takhar University)
}

\author{
${ }^{1}$ Sharifullah Ghafoori and ${ }^{2}$ Ainuddin Munib \\ ${ }^{1}$ Associate Professor of the Arabic Department at the Language and Literature Faculty, Takhar \\ University Afghanistan \\ ${ }^{2}$ Assistant Professor of the Arabic Department at the Language and Literature Faculty, Takhar \\ University Afghanistan \\ ${ }^{1}$ Sharifullah.ghafoori@gmail.com ${ }^{2}$ ainuddinmunib61@gmail.com
}

\begin{abstract}
Understanding and knowing the Arabic Language is the only way to know the Holy Qur'an and to delve deeper into its concepts, secrets and rulings because the Arabization of the Qur'an makes it is imperative for every Muslim to know and practice the Arabic Language, and familiarity with it leads the Islamic nation to the unity. The current state of the Arabic Language teaching in Afghan universities is a reassurance. Universities are constantly keen to develop curricula and methods of working with it, although universities have recently adopted several curricula to be taught within the project to develop the Arabic Language and its strategies in line with teaching skills. This study aimed to investigate on ways of practicing and learning the Arabic Language. The target was students of Arabic Language and Islamic studies of Takhar University. The research method is library-based method. The research during is the last semester to diagnose the aspects of ability and weaknesses in the curricula and university study methods. This study does not fulfill the desired purpose, but rather is a step along this path. Open the way, and always discuss what is on the scene. The system of teaching Arabic in Afghan universities faces critical challenges because it mostly focuses on old and reproduced curricula (translation and grammar), and because professors speak in the classroom in the national language (Persian and Pashto). Overlooking the teaching of the Arabic Language has increased, among Afghan youth.
\end{abstract}

Keywords: Arabic Language; language teaching; Arabic Department; Islamic studies; Afghan Universities.

\section{Introduction}

Praise to be God, Lord of the worlds, and prayers and peace be upon our Master, our Prophet Muhammad, and on his good and pure family and companions.

Then When the Arabic Language was a machine for understanding the Book of God and the Sunnah of His Messenger, may God bless him and grant him peace, it became obligatory for everyone who wanted to understand them to master Arabic.

Therefore, the teaching of the Arabic Language has become part of the religion because in its learning it is safe from distorting the recitation of the Great Book of God. Its knowledge is an awareness of the meanings of the Arabic word, and its glory speaks to those who listen to it. Those who know it are amazed, and those who ignore it are stumbling in their words. Their disbelief in their words, and he blamed him for establishing himself for a position that is not its people, and for the advancement of a platform that was not from his knights, and who intruded him to write while he was aware of it, and ignorant of its principles and rules.

The Arabic Language - the language of the Qur'an and religion - is still flourishing and spreading along with its plot to destroy it by the enemies of Islam. 
The importance of the subject becomes evident with the emergence of the great movement of translation from the second to the fifth century of migration and the translation of sciences that were written in the Greek Language in the world by people like Hanin bin Ishaq and his sons.

Note that the world in our time has become like a small village in terms of communications, and that science and creativity are advancing every day more than in the past, and because of the need for these sciences and creativity the necessity of learning the secondary language has increased greatly; especially the official language of the Islamic world, i.e. the Arabic Language, which is extremely important in Afghan universities since ancient times. In order to do that, it is necessary to plan scientifically to achieve success in the field of teaching Arabic.

Teaching Arabic like other languages requires planning on the basis of the prevailing patterns in the world, and not to take the wrong path today. It is necessary to analyze both the curriculum of education, the age of the learner and determine the beginning and the end of the time of education. The basic elements of the class, and choose the textual texts before undertaking scientific planning for teaching Arabic in Afghan universities. This article seeks to paint a picture of the situation required for teaching Arabic in Afghan universities. This can only be achieved by getting acquainted with the current situation so that we can establish its practical foundations.

Therefore, we have to understand where the shortcomings of our educational system lie when the students cannot read an unformed Arabic text and they have spent four years in a row learning their grammar; they cannot speak ten minutes without making mistakes. The current state of the curriculum needs to be revised and reformed.

Whereas the Arabic Language was an official language in our country, but it is sufficient for the teaching of the Arabic Language to prevail in the country as a secondary language. Thus, the people of Islamic Afghanistan can read Arabic newspapers and books, and the Arabs can read something of what is issued in Afghanistan in fluent Arabic. This new ingredient provides the opportunity for convergence of educational curricula and thinking curricula, as well as the opportunity to exchange ideas and literature. (Qutb, 1951, p 1).

\section{Background of the topic}

It is worth noting that the Arabic Language began mixing with the tongues of Afghans since the Islamic conquest by Al-Ahnaf bin Qais in the year 22 Hegiri.

Trade was one of the most important means for exchanging cultures and consolidating cultural relations, so Afghanistan was an important crossing for the transfer of commercial funds from India and China to the Arab countries and Egypt. Therefore, was the crossroads of cultures, and he said there were three ways of these commercial caravans. The most important of which was to connect Nishapur to the Afghan Herat, heading towards Sistan and Bust ending with the vast lands of Sindh. This requires getting acquainted with their tradition's forms, and the harmony of their language between each other. This harmony and mixing Were more in the cities and areas adjacent to those roads that the Arab caravans pass through, but specifically, I entered Arabic with the Islamic army, and since "the sun of Islam dawned," and in the name of Islam, Muslims advanced in their conquest in the name of Islam. It spread the Arabic Language. With the spread of Islam, and its literature in the countries of Islam in the land of Afghans" (Safi, 1988, pp 87-89). "The various people living in Afghanistan drank Islamic culture and reflected in the Arabic Language. Habibi: «It was not the general attack my Lord for the strength of his hardness conquering the lands, and controlling the country, but rather was a spiritual, moral and cultural conquest in the sense that the Arabic Language has become the language of science, culture and civilization. We see that after the passage of a century on the Islamic rule on this land that writing poetry and prose in local languages has vanished and ceased to exist, and hundreds of poets appeared. The writers, scholars, and investigators in the Arabic Language are among these Afghan khorasani, and they became famous in the Arab world that many matters and civilizational movements took control, and the cultural revival was in their hands. We saw that the Arab leaders practiced various policies to stabilize their feet, and fill the brains of the Afghan people have good Islamic principles, as they came with a number of jurists and preachers and on their head Al-Hassan Al-Basri - may God have mercy on him - and established the first mosque in the land of Sistanj, whenever they opened an area in which they built a mosque. They built most of these mosques to the places of ancient temples. These mosques were filled with residents, preachers and scholars. (Previous source, p 89).

Moreover, the Arab families who descended towards Khurasan either for help, work, or final emigration, were not separated in the apparent life, and were not gathered in a few points, especially 
for the Arabs. They did not choose the cities occupied by the conquering armies of cities and villages, but rather mixed with the people of Khurasan "and married women the Arabs have adapted to their new homeland. They felt that there was no difference between them and the people of the country in the common homeland between them, and they felt that they were Khorasani : They acquired their customs, traditions, and style of dress and eating. They received their lifestyle" as well, and the words were not on their part towards the Arabs in Khorasan One's block. They stood against the Arabs, the position of hostility or alienation. Rather, they interfered with them, and received their principles of tolerance and rational teachings. The two nations embraced the embrace of the two water droplets, and one of them melted in the second. so, all this created a suitable atmosphere for spreading the Arabic Language in all parts of the country. It went out to the streets, and in addition to this, the Arabic Language was the language of the state, politics and the bureau. (Herawi, 2014, p 2).

\section{Literature Review}

Within the limits of the researcher's knowledge of academic theses in the Arabic Language and literature, and through research centers and university journals, I did not find any study that dealt with "The Current Situation of Learning Arabic in University Departments and their Practices". Accordingly, there are no previous studies on this topic, but a number of articles were conducted on the importance of the Arabic Language in higher education stages, especially at the university level in Afghanistan. Some of them were aimed at obtaining a university academic promotion, as follows: Afghanistan and Arabic Literature through the ages by Dr. Muhammad Aman Safi, which was printed in Cairo in the year 1988, and a study presented to obtain the Ph.D.

\section{Between Programming and Language}

A definition of programming and language should be provided before we go into the topic:

A- Programming: Planners should prepare work programming after defining objectives in terms of quantity and quality and after selecting and arranging methods. Programming work or procedures is an accurate plan for the executive procedures that must be fulfilled in the future. (Mohsen Pour, 1377 p 43).

B- Language: The language is not a harmonious organ or system, as mentioned in the various books and articles presented in the forums of directors of departments of Arabic Language and literature in Afghan Universities, but rather is a mental preparation from which all human beings are granted, even if they are dumb or deaf; but the dumb and deaf benefit from gesture and gesture instead of sound image, all human beings have a language, but they differ from each other in the quality of speech, performance and dialect. We do not make mistakes in the language even if we called "well" when we want to call "high" because the error that occurred here is only in showing the external appearance; that is, we were wrong in the expression, not in the language.

Therefore, our present research when speaking of language is seen as an external manifestation of any speech, performance and dialect, and is expressed in language in harmony with existing books and articles.

\section{Education Curriculum}

We have indicated in the foregoing that one of the topics that must be analyzed is "the curriculum of education because the curriculum is the one that determines the causes of educational techniques and is the reason for the success or failure of education" (Mahkhi, 1370, p 16) The curriculum in this sense is a plan for a stage of study in an environment a certain school, or group of school stages, which informs young adults of the linguistic, behavioral, and intellectual level required to become beneficial members of their nation and society. The direct approach links them to a vision of things and beings to an intuition in understanding their characteristics, their changes, and by conceiving their similar relationships. (Buren, 1988, p82).

It was called "direct", based on the premise that there is an almost complete similarity between the acquisition of the mother language and the learning of the foreign language, which requires excluding the mediation of the mother language in the process of education, and relying directly on the target language (Yousfi, 2017, p. 2). The school curriculum required by Islamic Literature must be 
of its nature, characterized by its most important characteristics and characteristics and achieving its goals, and builds on its foundations and intellectual perceptions of the universe, life and man.

Because the curriculum takes place, after the student and the teacher's role, it must be modified before students become familiar with it.

The difficulty of learning the Arabic Language in the east lies in two things: the first is the way to teach the language, and the second is its rules. As for the method of teaching the language that Afghan schools and institutes conduct ineffective in teaching languages, the approach of the East Asian institutes in teaching Arabic and other languages must be followed. The second matter - grammar, is complicated by the level of students. The Arabs did not invade the rules, but rather they returned to their queens. As for the present generation, they lost the ability to speak Standard Arabic due to their dependence on slang. (Ghafoori, 1397, p 168).

The poor level of students in the Arabic Language department is due to the poor curriculum offered to students, as the current literature curriculum - for example - is invalid, so the student in the first year begins studying literature with a long research into the meaning of literature and the bad and bad style, and he memorizes from this what teachers teach from the terms. He does not understand its meaning. Regardless of the explanation made by the teacher. In the second year, he studies the second Abbasid era and the effects of literature in it, and they occupy the student with many historical information about the literature itself, so he memorizes the texts on the back of the heart without awareness of their significance; to answer the examination paper, the student memorizes the answer by heart!

Whenever we ask professors to leave the old curriculum and study their curricula by looking at modern patterns, they resist because the modern style and the old style are essential opposites. On this basis, the definition of the curriculum and its choice should have a high position in education. "Because much progress in the past three decades of language teaching in the world has been influenced by modern curricula." (Gallison, 1366, p. 55).

One of the most important principles of the direct curriculum in addition to employing language in appropriate natural contexts is to consider the number of students in the classroom, which is not available in most public schools. Focusing on oral audio skills may backfire with regard to other skills: writing and reading.

Literary experts in the field of humanities, and in particular the psychological and educational sciences, may indicate the importance of curricula and teaching methods, and the important role that curricula and teaching methods constitute in the educational and educational work. On the other hand, the curricula and teaching methods constitute the cornerstone of the development and modernization process, as the curricula and teaching methods work to achieve the teaching work and practice it in accordance with the requirements and needs of learners of different characteristics, educational stages, and study materials, with the aim of achieving the greatest degree of success of the educational goal.

\section{Directed Method}

As a result of a historical overview of language teaching, it becomes clear to us that a few pioneers such as Abul-Fath Osman bin Jeni and Abu Ali Al-Farsi teach the language on the basis of grammar and translation until the beginning of the third century Higiri, but language Education in Islamic countries witnessed a wonderful innovation in the late centuries represented in the use of the curriculum The so-called direct curriculum. The basis of this curriculum was that the mother tongue should never be used by students, and that the class should be active because education should be in the secondary language directly. (Al-Jahiz, 1423, p. 22) This means that the mother tongue constitutes the way of thinking of the child who acquires the language, and thought has only one method. If we try to teach him two or more languages, these languages will fight to control his thinking and compete with other languages for that to be his way of thinking.

Hobbyists believe that this curriculum is not measured in relation to other curricula such as "grammar and translation". The direct method was established by establishing an international conference for contemporary languages in Wayne in the year 1898, and the use of modern origins for advanced language classes was approved at a conference held in Leipzig in 1900, namely:

1. To avoid using the mother tongue in class as much as possible.

2. The textual texts must be drawn from the secondary language culture taught. 


\section{Modern literary texts and written practices be added to the exercises.}

The Ministry of General Education announced to the Government of France an official communication that the direct curriculum is the only curriculum for teaching the foreign language. This approach was found popular in Germany after the propaganda of individuals such as Hartmann and Kuhn's priests and mixed it with the old curricula where it was called "choosing the best" if it is true. The direct curriculum was used in England for desire and success in the attempts of people such as Findlay and developed throughout the years 1899to 1924 (Mahky, 1370, p 26).

Despite all of this, he used the "method of translation and grammar" in America until the Second World War, and it was natural for language teaching in America to be backward for Europe. Teaching languages is also a linguistic investigation. (Gallison, 1366, p. 59).

But here an important question arises: Does the direct approach have shortcomings or defects despite all these positive advantages?

When students learn a language quickly, they should not stop linguistic practice or forget about it, and if they find an environment in school and university that is similar to the environment of learning a mother tongue, but they have forgotten that students and students in school and university learn the grammatical rules of the mother language as well. Why do they not learn the grammar of the foreign language?

Because the one who does not learn grammatical grammar cannot know the written language, therefore omitting the teaching of grammatical grammar in secondary language learning is messing to the extent that he has made it the primary basis for learning.

Science and work must accompany and place work at the top level. It is only science and work that can produce better data than the direct curriculum. The failed results of secondary school education arise from language professors using the translation approach and the grammar that they should have left from previous years. However, since the direct curriculum is not convincing either, a third method must be used in which learning of theoretical principles follows the practical practices. The teacher must teach that practicing dialogue and writing is the only way to be familiar with the language and to find the direct link between language and idea. Language education should be planned on the basis that translation and grammar are a means to accelerate language proficiency and permanence and not to be an end in itself. There is no merit in linguistics without its verbal customs and practical skills. (Beliaf, 1368, pp 23-21).

Montaigne indicates in one of his articles that he learned the Latin Language without learning the grammatical rules because his father had forced all his family and teacher to speak in the Latin Language alone; He forgot the Latin Language he used to speak with his divorce" (Mahki, 1370, p20).

It is necessary for the professor to know that the lack of a direct approach is due to the limitation of this approach to work, and the neglect of the theoretical side.

\section{The Age of the Learner and Determining}

Psychologists have proven that it is better to start studying a foreign language from an early stage because it is easier to learn and to last more. "Research shows that if a learner enters the hospitable country before the age of maturity, he is learning the language of that country like his children. It was also proven in the research carried out by Oyama that the age of entry to the host country - not the period of residence - is the one that influences the mastery of the language" (Mubasheer, 1374, p14) However, the child must not learn both the mother language and the secondary language together, because it harms His verbal and intellectual development developed a lot.

And he has the problem of overlap because the traditions of the mother tongue have taken root in his mind. Some also see that «the search for learning two foreign languages together leads to each other pushing each other back and affecting the learning process negatively. It is necessary for the learner to start learning a second foreign language after the first secondary language, which he has finished learning in two or three years" (Beliaf, 1368, p27).

The origin of the altar and the passage of it: Its principle is the time when man does not benefit from the spoken traditions and skills. The study of the secondary language must start from the spoken language to the written language. And its end is from the moment the student begins to think in that language. Because understanding the language occurs through listening to it, the learner can easily express his thoughts in the foreign language.

The professor should strive to develop in students the ability to think in a secondary language and a linguistic faculty. Because students can only learn a language as a means of communication after 
they make a direct link between language and reasoning. Rather, the true connection between language and thinking depends on the absence of a separation between listening to the word and understanding its meaning. It also depends on the ability of students to use grammatical rules to express their ideas and opinions.

\section{Learning stages}

Although language experts divide the stages of learning into three: "clarifying the new topic for students," "taking students the modern topic" and "re-innovation by students" (ibid., P. 5), in reality, learning has five basic stages, which are:

1. Redefinition: The purpose of redefinition is to distinguish the learner from one other, and to realize that the sentence presented is a repetition of the sentence the speaker said earlier or a new phrase that differs from the previous phrase.

2. Imitation: It is the duty of the learner to repeat at this stage those expressions that he sought to learn. It is better to mimic the words in the sentence, even if the sentence is simple, instead of telling the word alone. Because first he learned the word in the sentence, he is a university student: A simpler example. Second: The performance of the word in the sentence is normal. Finally, the student learns basic grammatical information and pronunciation together.

3. Repetition: The main work in the stage of repetition is to take the mental gravity - conscious control of all parts of the sentence - from the learner until it is concluded because the speaker when he thinks about the way out of the letters does not reach the integrity of the statement and is not ready to move towards the fourth stage. If we had to think about all of our muscle movements while walking, you could not walk comfortably.

4. Variation: The learner must change patterns. For example, instead of repeating the professor's words as a parrot, he changes the phrase "he is a college student" to "she is a college student" and the professor also, instead of converting the alteration of circumstances to the learner, must benefit from three. Practices are: a. Substitution drill b. Transformation drill c. Installation practice (Combinatorial drill).

5. Selection: The learner has learned to redefine the expression formulation and simulation. He practiced this form in a way that he could benefit automatically without pause. Likewise, he has learned to switch phrasing to other phrases. Now he has to learn when to use it. This stage includes understanding the meaning and social function of speech; do you use this phrase in formal or informal relationships? Is this phrase specific to performing respect or other imperatives? (Documb, $1364 \mathrm{p} \mathrm{65)}$ ).

\section{Class Rectifiers}

The original components of the class are: the student, the teacher, and the curriculum.

A. Thousand Student: There is no doubt that we can influence the students 'willingness and desire to learn. This topic facilitates the learning process. If we acknowledge that the student is the most important pillar of the class, and the purpose of establishing the university is to teach it, and if we truly respect its reasonable requirements, then we can change its viewpoint to the lesson and in the end we can accelerate the learning process.

B. Professor: Many experts argue that the professor is the most important pillar in the class because the method is not fateful if the professor is not aware of the educational techniques of language and a science of linguistics and psychology. "Because the curriculum is only a tool, and the consideration of it depends on the proficiency of the professor." (Mahhki, 1370, p. 15) For example, the inability of teachers and professors to speak in the Arabic Language is one of the reasons that led to the ineffectiveness of the "direct curriculum."

Although we can qualify the teacher and the professor well in his study time in terms of language teaching, linguistics and the rules of education, but the idea of the adequacy of the teachings at the university is never true, especially in the period when science and arts develop very quickly. The professor must always strive to develop his information according to modern technology. Therefore, he must apply the idea of continuous learning that had been known by St.Juston Berger. (Gallison, 1366, p. 54). Because language is such a complex aspect of astonishing human being that it cannot be said that a person with a balance of innate abilities can learn the Surface Structure and the Deep Structure of it. 
Brown emphasizes the need for continuous learning, says Majd al-Din al-Kaiwani that the professor should not take the opinions of others in his craft as a key with which he can open all of his closed locks. Rather, it is correct to express theories based on reading others' opinions about language teaching and testing it at work. (Brown, 1363, p 11).

C. The curriculum: The curriculum is the third pillar of the class and we have mentioned it earlier.

\section{Choose a Subject}

The following notes should be observed in the selection of academic subjects:

A. The primary materials of education should be repeated so that the learner understands them. The use of valid curricula such as explanation, clarification, repetition practices, arbitration and oversight practices are a duty in every lesson and for each stage of learning.

B. The professor should be more interested in the daily oral and written language because the purpose of language education is for learners to learn to speak and understand the audio outside the university (Gallison, 1366 p 26). The professor should as naturally as possible, be kind to the students, take care of their best interests, solve their problem in a calm manner, and make the complaint the last solution.

C. The professor must have a balance in his hand that weighs the student's mind and the degree of his willingness to accept what he says. The teacher must gradually progress in his style with the beginner, and then gradually take him up to the point where he can realize the precise meanings. (Mubasher, 1903, p621)

D. The course materials should be coordinated to conclude each session from class to session. The selection of academic subjects from modern texts displays the class naturally and physically. In addition to that it causes the professor to use advanced electronic mechanisms to record and produce speech again easily.

E. It is imperative that the ancient and scattered texts be used to teach a foreign language, so it is not reasonable to study the shrines of the Hariri for the beginner student because literature is an emotional subject and full of taste and sore and therefore difficult to understand on the foreign learner. "A good movement led by James Hamilton and a number of others occurred in the time of the nineteenth century, but this movement was defeated by the choice of literary texts and texts from the Bible for young men." (Mahki, 1370, p22)

F. The choice of grammar will depend on how much it is used in the language and learners' needs. For example, it is not necessary to study the effect with it in the first and second stages. Finally, when composing textbooks for different levels of university study, attention must be paid to the learner's age, level, needs, and available time for teaching.

\section{Teaching Arabic in Afghanistan}

We mentioned in the foregoing that the Arabic Language has a special place among the Afghan people that the widespread spread of the Arabic Language in Islamic Afghanistan from the lowest to the maximum did not stop at the self-desire and religious enthusiasm of Afghan citizens. However rather the government's care that it was based on the establishment of Islamic schools, such as The Arab Science House in Kabul which had a great influence in this area. The establishment of the International Islamic University in the neighboring town - in Islamabad - in the early eighties in the financing of Arabic also had the greatest impact in spreading the Arabic Language among Afghan Mujahideen and lovers of the Arabic Language, especially since this university adopts Arabic as the language of study in a number of disciplines. Teaching in Afghan schools and universities was usually free. Although the Afghan government made education compulsory for all citizens. Some families began bribing education officials, so some parents not only sent their children to government schools, but also sought to pay school fees as their children might get a better education. Education has become a somewhat symbolic battle in domestic politics as well.

The continued flow of Afghan labor to the Arab labor markets - especially the Gulf ones contributed to documenting the relationship of the Islamic peoples with each other through the Arabic Language, which is the most important gains from this communication.

Because of this trend, the continuous commercial relations between the Arab countries and Afghanistan, as well as the Arab traders to Afghanistan and those residing in Afghanistan, became teachers of their language as a result of the demand of their Afghan lovers to teach them, even at the 
level of one word per day. This was aided by the fact that at least $\% 60$ of the vocabulary of the local Afghan languages - Persian, Pashto and Uzbek - are Arabic.

It also played an important role for the delegation of Arab institutions in spreading the Arabic Language over the past twenty years in Afghanistan by opening Arabic teaching institutes, providing Arab teachers and setting up Arabic Language courses in various parts of the country. In addition to sending hundreds of students to Arab countries to complete their studies there, as well as a role orphan schools, which adopted Arab curricula and the number of students exceeded 9thousand students.

But the question that arises here is: Is language taught in Afghan society based on scientific planning or not?

The truth is that the teaching of the Arabic Language in Afghan Universities- especially in universities that choose in the Arabic Language section of the College of Arts and the Department of Islamic Studies at the College of Sharia- is carried out on the basis of correct scientific planning, and that its education in Afghan schools and universities, despite the presence of a number of pitiful teachers and professors, Were not met. A complete success so far. Although it is not possible to fully investigate all the reasons leading to this, we do show our allowances in this field, taking advantage of what is available in the world today from scientific planning for teaching secondary languages, and we compare it with what is happening in our country.

Old methods need to be developed and improved over time. so that they can resist modern methods. For example, teaching the Arabic Language on the basis of the copied curricula such as "Grammar Translation" has played its role and its maximum impact for years from the curricula of universities in the universities of the Western world, but it was and still prevails on our educational system and university curricula. Our second language education needs are not met, but we use it today without any change or development.

"Evelyn Hatch, who emphasizes the harms of grammatical rules in the language teaching process, said: The teaching of the second language was based on the grammar approach to grammar until our time. He learns how to use these phrases in his speech after a long period, while it is useful to reverse it, that is, for the student to learn the conversation in the beginning and the grammatical rules after it (Brown, 1363, p239).

The teaching methods create, elevate, weaken and disappear, and the resilience of one curriculum in front of other curricula needs to be studied, removing negative aspects and strengthening positive aspects. Universities have an important role in modernizing, expanding and creating vitality for these educational curricula. Universities are important and modern centers for the production of science and electronic renaissance, and they play an essential role that is undeniable. The completion of this project by the graduate studies centers requires that the professors be serious, creative and closely related to the successful universities in the world in order to benefit from the modern educational curricula.

Unfortunately, however, the issue of "creativity" in our universities is limited to experimental sciences, such as engineering, medicine, and the like. We can say that books that were written years ago in medicine, engineering, and computers are not currently beneficial to us, while "creativity" in the humanities has been neglected for centuries until now, as if it has become Forget a forgotten one (Ahmady, 2012, p 4).

We have to understand the causes of underdevelopment in our educational system, so what is the reason that a student who has spent four university years of his life teaching Arabic is unable to read an unformed Arabic text, just as he cannot speak ten minutes without error, even though he is a glorious student he obtained high marks in the exam. Unfortunately, sometimes the learner cannot read the text that constitutes the Holy Quran. Perhaps the main reason for this flagrant failure is that we only care about teaching morphological and grammatical rules, and at the end of the chapter we conduct an exam in the framework of questions such as: What is the subject's name or the object's name for the word? Without practicing the student or student practically in applying these rules to the texts, the learner forgets everything he learned after two months or more, while he has obtained a high degree in the exam. This does not mean the elimination of lessons such as grammar, exchange and rhetoric from the academic subjects, but rather that the professor is not speaking alone in the classroom until his lesson is practical. Perhaps the main reason for this flagrant failure is due to the different goals of the university. Some universities aim to produce students who teach the Arabic Language for their gender, and that is why after the learner finishes the first stage, he will move to study a program for a period ranging from two to four years in which educational materials will 
prevail. Some universities are interested in studying what is known as the "specialized language" that prepares the student and helps him to continue his studies in the college he wants.

While we find that the goal of Islamic studies is a subsidiary goal and not an authentic one in many universities concerned with teaching Arabic in Afghanistan.

This is a negative reason and an impediment to the giving of the student who was unable to continue his university studies or was devoted educationally to be a teacher of the Arabic Language in his country or other what he needs in his life what he offers to his fellow citizens.

That is why it is so important to emphasize and ensure the importance of Islamic studies for learners of the Arabic Language and to increase its courses and hours while ensuring that its teachers are qualified to deliver this material by successful means and a useful method.

When the professor talks alone, all students are caught off guard and silent, writing about the process of teaching the language to fail and fail. The reasons for this failure are:

A. The Arab lessons and rules throughout the middle and secondary levels to university are almost repetitive and differ slightly in the secondary stage relative to the medium, and in the university in view of the secondary. A group of textbook authors and university professors should author books on teaching Arabic with a comprehensive view of the intermediate, secondary, and university levels in a future project in which iterates duplicates and achieves at each stage its own expectations.

B. That exchange and grammar occupies the largest space in Arabic books in the introductory and university stages and it lacks conversation. The teacher in the school never speaks Arabic, and a few professors speak Arabic in the university, where the class is boring, and the teaching process is not a queen in the learner's mind.

If the teacher and the teacher in the class speak Arabic, students hear hundreds of Arabic words in each class; they wish to speak Arabic over time gradually; that we force them to speak in Arabic because they are forced to adapt to the conditions of the class so that when they enter the class they feel that they have Entered an Arab country. Doing this in the first months is difficult, but there is no doubt that success is our ally if we persevere in it.

Advanced studies indicate that one of the classes in each school specializes in teaching Arabic or English throughout the week. This helps the pupils' ability to call, undeniably.

C. The question that the Arabic Language teacher always faces is "What is the benefit of studying the Arabic Language?" And this results from not showing us the benefits of studying this language and the related professions. More often than not, the students do not receive an accurate answer; they go to the conclusion that they are of no use and do not feel motivated to teach them.

We must feel responsibility for national benefits and capital, especially the hidden capabilities of science researchers, and change the incentive for education represented in obtaining university degrees to seek knowledge as a virtue. It must explain all the benefits of this language and the possibilities in it for learners, the professions that result from learning Arabic.

\section{The Changes Required to Teach Arabic in Afghan Universities}

After talking about the necessity of scientific planning for language education on the basis of modern curricula, and after learning about some of the problems and deficiencies that the Arabic Language teaching process faces in Afghan Universities, mention the changes required to raise these problems and shortcomings in four areas:

1. The necessity of changing the curricula of language teaching in Afghan universities, and using a curriculum that is a mixture of conversation, grammar and translation with a focus on the "direct curriculum", taking into account in the following points:

- That the teacher speaks in the classroom in Arabic.

- The students speak with the teacher in Arabic from the second semester.

- The students must adhere to speak Arabic from the second year inside and outside the university.

2. That the academic subjects are compatible with the aims of teaching the Arabic Language, and that the following observations are observed:

- That the academic subjects for the introductory stage and the first year of the university not be dry literary lessons. 
- That the texts include the daily and cultural issues, customs and traditions prevailing in Afghan cities with their own images, so that they affect learners intellectually and psychologically. (Ghafoori, 1397, pp167-169)

- The texts should be valid for understanding, the different educational stages and their curricula.

- The texts should be arranged in scientific order.

- To choose the rules according to the estimation of their use in learning the Arabic Language.

3. Educational settings (educational techniques):

- That an administrative order be issued by the Ministry of Higher Education to the Department of Modern Technologies for Universities using a projector for all areas of education, especially for teaching Arabic and English in university levels.

As one experimenter says, language learning about the role of this potential in the field of second language learning: assistive devices for education are a bridge between the class and the outside world. Audio-visual machines are required to teach the Arabic Language.

4.The Lecturer:

That the professor does not speak in class alone and that students participate in the class.

- That the professor takes an interest in reading and studying daily and takes advantage of modern creations of language teaching and learns new curricula in teaching.

\section{The result}

It is possible to draw from this inductive study useful foundations and approaches that help in teaching and learning the language. If we want to direct descriptive works of benefit accurately and intelligently, the mission of the linguist ends as soon as he provides us with all his descriptive works, and beyond. From the qualifications of a multiple and varied language teacher, he must first be aware of the language he is studying, and can speak and understand it as his native language, or slightly less. He must also have some knowledge of contemporary Arabic.

The system of teaching Arabic in Afghan universities faces critical challenges because it mostly focuses on old and reproduced curricula (translation and grammar), and because professors speak in the classroom in the national language (Persian and Pashto).

Although the Department of Arabic Language at the University of Kabul has been able to make good strides in this area using modern technologies in education, these endeavors have not met with great success because overcoming obstacles and challenges that exist requires scientific communication among university professors and requires the work of the group. Also, students should be taught how to learn on their own, as experiences have shown that the lessons one learns on its own are the best that they receive in life.

In recent times, the percentage of attendance at the experimental and linguistic institutes that overlook the teaching of the Arabic Language has increased and was one of the most prominent factors in the weak position of the Arabic Language among Afghan youth.

Contributing to raising linguistic awareness, improving linguistic competence, developing communication skills for workers in vital sectors and encouraging and supporting researchers to conduct research and studies on contemporary linguistic issues and phenomena in addition to strengthening the relationship and achieving partnership with international research centers specialized in applied linguistics.

I ask God to appoint and reconcile officials, caretakers and those interested in matters of teaching Arabic Language and religious sciences for the children of Muslims to accept them bless their efforts, and facilitate the succession of the two predecessors.

\section{Recommendations and Suggestions}

At that time, we realized that the methods that were developed to teach the Arabic Language in the Ministry of Higher Education did not meet our needs in education. It is necessary that we use the various methods of language teaching and derive the place and contemporary educational techniques because the method of education will not be constant throughout life. So, we will change it gradually with the development of methods and the development of techniques its new curricula in the world. 
We ask Arab governments and Arab and Muslim brothers to return to Afghanistan and revive previous memories and benefit from this ruling atmosphere in Afghanistan by establishing universities, educational centers and public libraries with the acceptance of a generation of students in Arab Universities, more than before. We invite them to cultural jihad and the establishment of scientific satellite channels to spread religion and Sunnah among the general public.

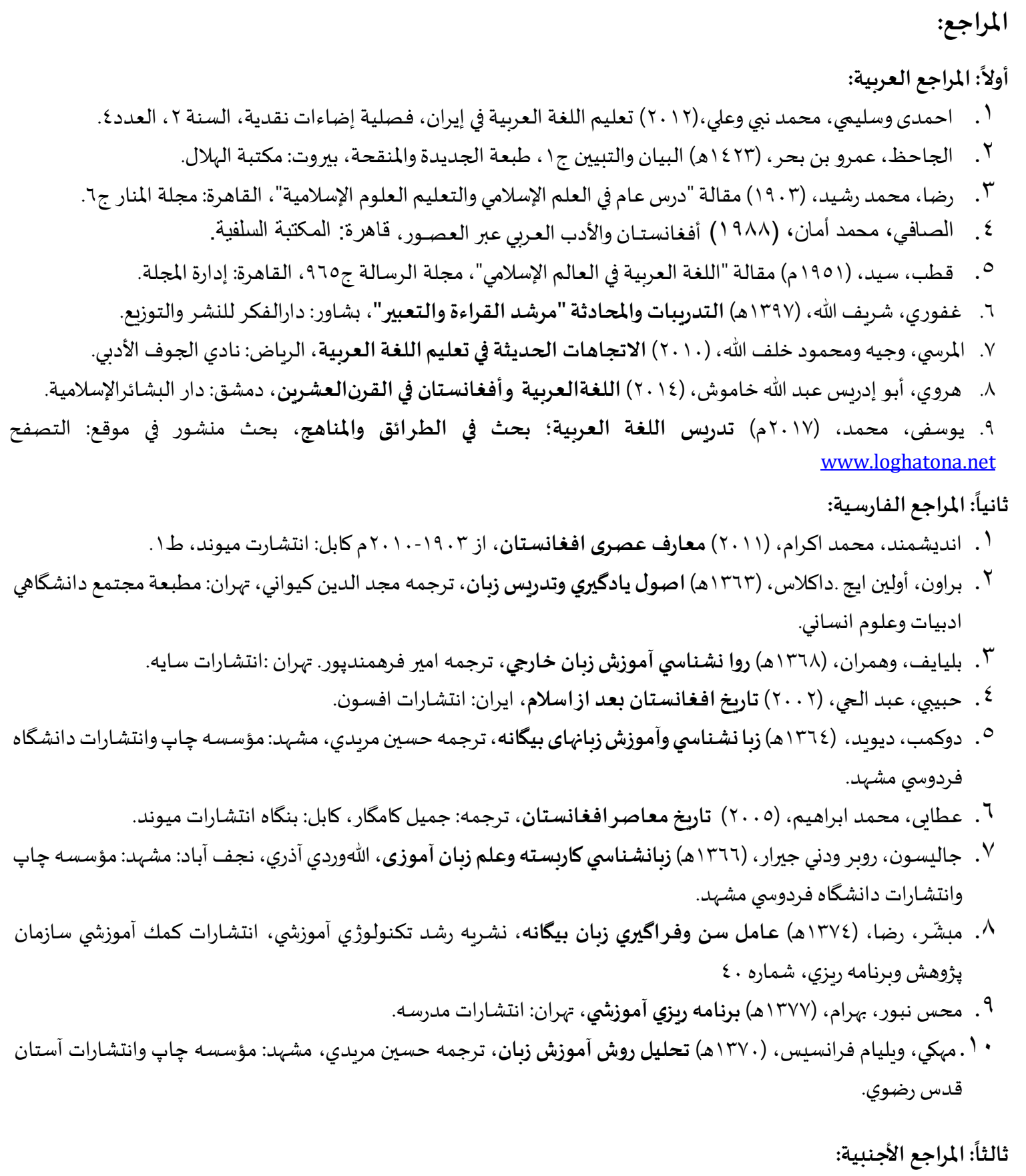

[1] Ataye. M. Ibahem, Tarikh-e muasir-i Afghanistan, (Translator to Persian. Jameel Kamgar), Kabul: Bingah Entesharat-e Maktbaa-yi Maywand, (2005)

[2] Andishmand. M. E., Maarif-e Asri-yi Afghanistan (1903-2010). Kabul: Entesharat-e Maywand, (2011)

[3] Brown. Olin H. Douglas., The Origins of Yadjiri and Teaching Zeban, (Translator to Persian Majd Al-Din Kiwani), Tehran: The Prentead Society of Daneshgahi Literature and Humanities, (1363)

[4] Believ \& authores, Roanashnassi Amozushe Zabbane Begana, (Translator to Persian Amir Farahmandfor), Tehran: Entisharat-e Sayeh, (1368) 
[5] Ducumb. David, Zebanashnasi and Amuzsh Zebanhay beganah, (Translator to Persian Hussein Mureidi), Iran: Entisharat-e Ferdowsi University Mashhad, (1364)

[6] Habibi. Abdulhay, Tarih-e Afghanistan ba'd az Islam. Iran: Entisharat-e Afsoon, (2002)

[7] Gallison. Roper \& Denny. Jerrar, ZabanaShnasi Karbsteh wa- Aalum Zaban Amuozi, (Translator to Persian Allahwerdy Azeri), Najafabad Mashhad: Entisharat-e Ferdowsi University Mashhad, (1366)

[8] Mubasheer. Reza, Aamel seyn -wa- Faragiry Zabban Begana, Rushd and Technology Technology Magazine, Distances of kumak, Amozami Sazman, Wohash and his program Rize, Vol 40(1374).

[9] Mohsenpur. Bahram, Barnama-Haye Amuozshy, Tehran: Entisharat-e Maddrassa, (1377)

[10] Mahki. William Francis, Tahlil-e- Rovushe Amouzushe Zabban, (Translator to Persian Hussein Maridi), Mashhad: Entisharat-e Astan Quds Razavi, (1370)

[11] Puren. Christian, Histoire des méthodologiesde, l'enseignement des langues, paris, Nathan- CLE, international, (1988) 


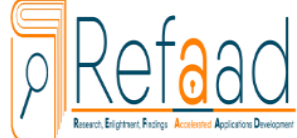

www.refaad.com
المجلة الدولية للدراسـات اللغوبة والأدبية العربية

International Journal for Arabic Linguistics and Literature Studies (JALLS)

Journal Homepage: https://www.refaad.com/views/JALS/home.aspx ISSN: 2663-5860(Online) 2663-5852(Print)

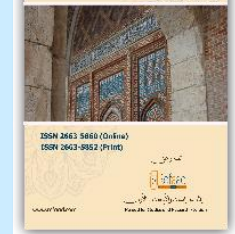

\title{
الوضع الحالي لِتعلّمِ اللغة العربية في الأقسـام الجامعية وممارسـاتها \\ (قسم اللغة العربية والدراسـات الإسـامية التابع بجامعة تخار أنموذجًا)
}

\author{
شريف الله غفوري \\ أستاذ المشارك في قسم اللغة العربية بكلية اللغات والآداب- جامعة تخار - أفغانستان \\ sharifullah.ghafoori@gmail.com
}

عين الدين منيب

أستاذ المعيد في قسم اللغة العربية بكلية اللغات والآداب- جامعة تخار - أفغانستان

ainuddinmunib61@gmail.com

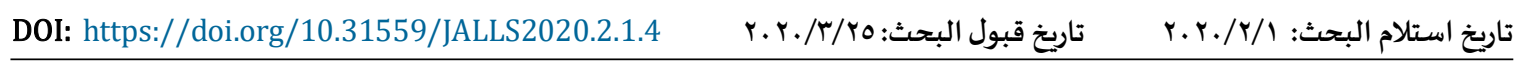

الملتخص:

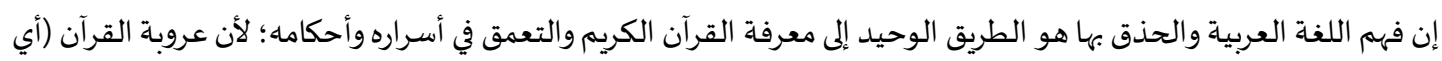

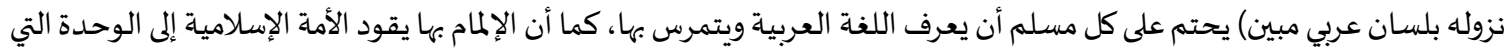

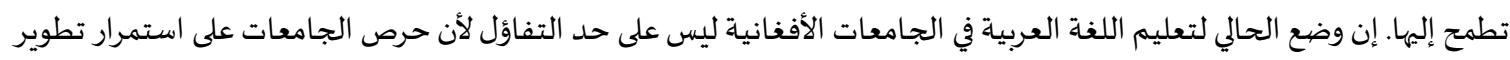

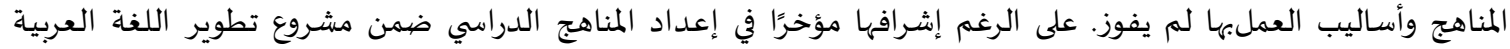

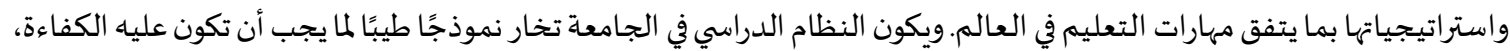

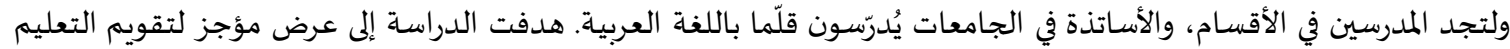

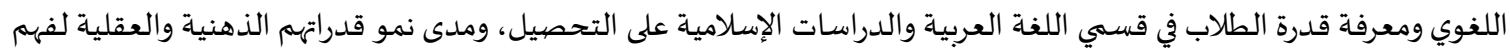

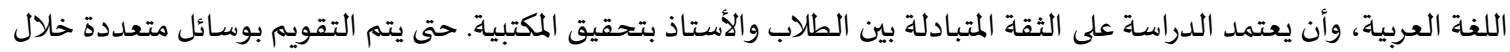

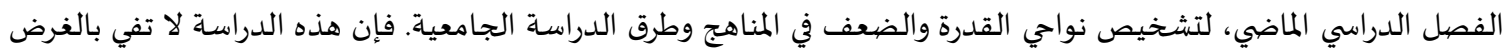

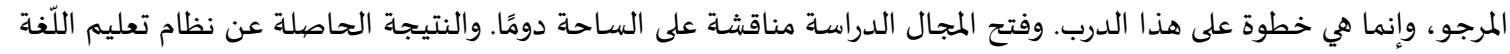

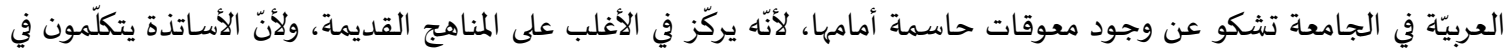

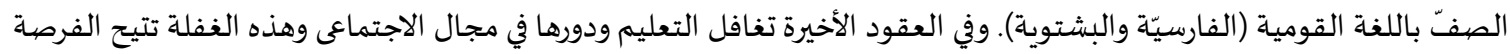

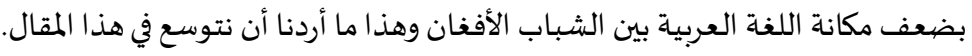

الكلمات المفتاحية: اللغة العربية؛ وضع تدريس العربية؛ قسم العربي؛ الدراسات الإسلامية؛ الجامعات الأفغانية. 